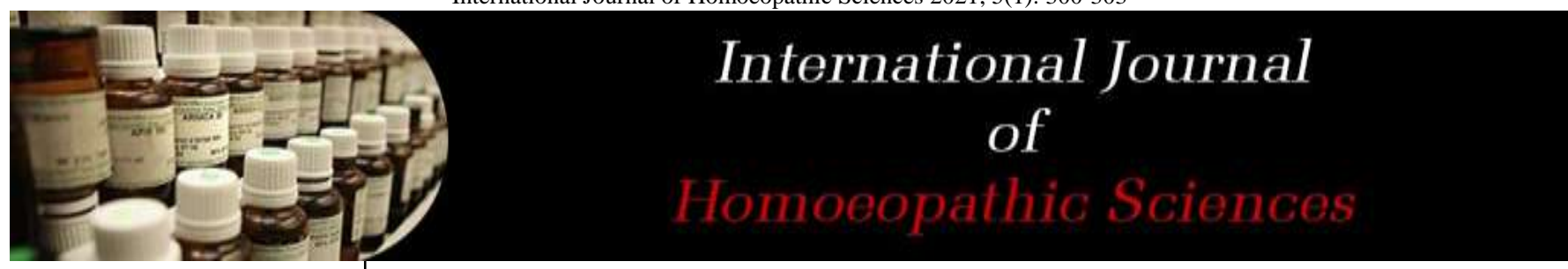

E-ISSN: $2616-4493$ P-ISSN: 2616-4485 www.homoeopathicjournal.com IJHS 2021; 5(1): 300-303 Received: 19-12-2020 Accepted: 27-01-2021

Dr. Archana B Dahat MD Part-I, Organon of Medicine, Guru Mishri Homoeopathic Medical College, Shelgaon, Jalna, Maharashtra, India

Corresponding Author: Dr. Archana B Dahat MD Part -I, Organon of Medicine, Guru Mishri Homoeopathic Medical College, Shelgaon, Jalna, Maharashtra, India

\section{An overview of asthma and its miasmatic classification}

\section{Dr. Archana B Dahat}

DOI: $\underline{\text { https://doi.org/10.33545/26164485.2021.v5.i1e.331 }}$

\begin{abstract}
Asthma is the most common respiratory disorder. Despite significant improvement in the diagnosis and management of the disorder, the majority patients with asthma remain poorly controlled. In most patients, however, control can be achieved through use of avoidance measures and appropriate pharmacological interventions. The most prevalent type of asthma is characterized by eosinophildominated inflammation. Homoeopathic management of the same can lay an excellent ground for the treatment of asthma as an allergic disorder. This article provides a review of current literature (taken up from standardized medical text books) and guidelines for the appropriate diagnosis and management of asthma.
\end{abstract}

Keywords: Asthma, miasmatic classification, poorly controlled

\section{Introduction}

A condition in which a person's airways become inflamed, narrow and swell produce extra mucus, which makes it difficult to breathe (NCBI website). Asthma can be minor or it can interfere with daily activities. In some cases, it may lead to a life threatening attack. (asthma, online). Asthma is one of the major public health problems for the developed and developing countries. Worldwide, it is estimated that 300 million people are affected with bronchial asthma. India has an estimated 15-20 million asthmatics with a prevalence of about $10 \%$ and $15 \%$ in 5-11 year old children (Science report). Subbarao et al. (2009) studied astama epidemiology, etiology and risk factors.

\section{Literature review}

The word 'asthma' is derived from the Greek meaning ' panting' or 'labored breathing'. Asthma is a condition characterized by a paroxysmal wheezing respiration dyspnoea (difficulty in breathing), mainly expiratory.

\section{Asthma - Causes}

According to the etiology, bronchial asthma is divided in the following groups:

1. Allergic (extrinsic/ atopic) Asthma - This type of asthma usually starts in childhood and is often preceded by eczema. But most of the young adults ( $<35 \mathrm{yrs})$ developing asthma also fall in this category. Genetic factors also play a significant role $\mathrm{i}$ this. In this type of asthma the allergen leads to production of excessive (IgE) immunoglobulins.

2. Infective or Intrinsic Asthma - This is not hereditary or allergic, but may be caused by, or at least associated with upper respiratory tract or bronchial infection which is usually viral.

3. Emotional Asthma - Psychological factors (like anxiety, emotional stress etc) are often considered to be the sole cause of some asthmatic attacks, but it is still not certain whether it can be the sole cause or is only a precipitating factor.

4. Occupational asthma - This can occur in certain industries in which there is exposure to metallic dusts (esp. platinum salts), biological detergents, toluene diisocyanate, polyurethane, flour and dust from grains etc. India has an estimated 15-20 million asthmatics with a prevalence of about $10 \%$ and $15 \%$ in $5-11$ year old children ${ }^{[1]}$. (Sharma et al., 2016).

What ever may be the cause, it ultimately leads to paroxysms of bronchial obstruction produced by widespread bronchial spasm accentuated by plugging of the bronchi with excessive mucus.

Asthma - signs and symptoms

Recurrent episode of paroxysmal dyspnoea (difficulty in breathing) 
The breathing is laboured, with a wheezing sound, mainly on expiration.

Asthma attacks often occur in the early hours of morning (when there is no immediate precipitating cause). During the attack patients often prefers to sit then lie down.

\section{Asthma - Diagnosis}

Diagnosis can usually be made clinically by a competent doctor. Allergen sensitivity tests, X-ray, spirometry, sputum and blood tests etc may be of use in finding the cause and severity of the condition.

\author{
Asthma - Differential Diagnosis \\ Bronchitis \\ Cardiac asthma \\ Renal asthma \\ Isolated attacks of non-paroxysmal dyspnoea.
}

\section{Asthma - Complications}

Apart from chronicity, usually no complications.

Pneumothorax, emphysema, or areas of consolidation or pulmonary collapse may occur in very advanced cases.

\section{Asthma - Conventional treatment}

Bronchodilators, anti-allergic drugs, and corticosteroids are commonly used to provide symptomatic relief.

\section{Asthma - Lifestyle and Diet}

Advise for the patient:

Avoid the allergens they are sensitive to.

Do regular light exercise like brisk walking or jogging. Heavy exercise can precipitate an attack of asthma, so always do mild exercise without putting too much strain on your body.

Learn breathing exercises to improve lung capacity of especial use is 'pranayam', a yoga exercise.

Learn some stress relieving exercises, meditation, or yoga to minimize the psychological factors related to disease.

Eat healthy, nourishing and well balanced diet.

\section{Asthma - Homeopathy Treatment \& Homeopathic Remedies}

Homoeopathy is the second most widely used CAM in healthcare systems according to the World Health Organization. (Jonas et al., 1999) Studies have shown that homoeopathic treatment for respiratory diseases was associated with a significant reduction in the use and costs of conventional drugs (Rossi et al., 2009) Homeopathy has remained one of the most widespread and controversial forms of complementary medicine and is used to treat asthma. The prevalence estimates of com-plementary therapy use for asthma vary widely, from 6 to $70 \%{ }^{[1-3]}$. However, the clinical evidence remains uncon-vincing regarding the effectiveness of complementary ther-apies and homeopathy for asthma ${ }^{[4]}$. In addition, system-atic reviews identified the paucity of high-quality random-ized controlled trials in homeopathy ${ }^{[5-13]}$. General Approach While dealing with a case of asthma, we not only record the symptoms of the disease but also study the medical history, family history, physical and psychological characteristics of a person. This helps to find the cause, the precipitating factors, and the hereditary tendency etc. Of special interest is the history of suppression of skin disease. There is always a tendency or predisposition for a disease - it first manifests on the less vital organs, towards the periphery (like skin). If this manifestation is suppressed then the disease shifts inwards, towards the more vital organs (like lungs, heart, brain etc).

The fact that in children asthma is often preceded by eczema is observed by the allopaths also. They say that children often 'move-out' of eczema and 'move-into' asthma. But they are unable to make a correlation. The suppression of eczema with topical preparations, does not cure the disease/sensitivity of the person, it merely drives it inwards. Remedies:

Some of the common medicines are ars-alb, ipecac, lachesis, pulsatilla, spongia, sulphur, ignatia, antim-tart, hepar-sulph, nat-sulph, tuberculinum etc. The selection of medicine varies from patient to patient.

\section{Miasmatic classification}

It is absolutely necessary for a homoeopath to understand the nature of the exciting causes of bronchial asthma, the allergic triggers as well as the underlying fundamental cause of bronchial asthma which is usually due to the chronic miasms. An acquired usually psoric origin and genetic has the sycotic base. The acute exacerbations of the chronic state are latent within the constitution and have been brought by exciting factors. 
Table 1: Shows symptoms

\begin{tabular}{|c|c|c|c|c|}
\hline Symptoms & Psora & Peudo psora & Sycotic & Syphilitic \\
\hline Sneezing & + & & & \\
\hline Wheezing & + & + & & \\
\hline Cough & + & + & & \\
\hline Expectoration & + & + & & \\
\hline Shortness of breath & + & & & \\
\hline Chest pain & + & + & & + \\
\hline Tiredness, Weakness & + & & & \\
\hline Cyanosis & + & + & & + \\
\hline Digital Clubbing & + & & + & \\
\hline Telangiectasia & + & + & + & \\
\hline$X$ ray findings & Normal & $\begin{array}{l}\text { Sings of inflammation } \\
\text { Lymph node enlargement }\end{array}$ & $\begin{array}{l}\text { Signs of effusion } \\
\text { Gaseous effusion }\end{array}$ & $\begin{array}{l}\text { Signs of } \\
\text { Haemorrhage }\end{array}$ \\
\hline
\end{tabular}

Each of the chronic miasms has their own characteristic signs that are an integral part of the totality of the symptoms. Psora tends to produce to irritation, inflammation, and hypersensitivity and Pseudo-psora tends toward suppuration Sycosis tends to produce infiltrations, indurations, and over growth and Syphilis tends toward granulation, degeneration and ulceration.

\section{Concussion}

Asthma is the most common respiratory disorder which should be suspected in patients with recurrent cough, wheeze, chest tightness and dyspnea, and should be confirmed using objective measures of lung function. Allergy testing is highly recommended to identify its possible triggers. All asthmatics should have regular follow up visits during which criteria for asthma control, adherence to therapy (conventional or homoeopathic) and proper inhaler technique, if in use, should be revived.

\section{Financial Support and Scholarship: Nil}

Conflicts of interest: There are no conflicts of interest.

\section{References}

1. Epidemiology and costs of chronic obstruction pulmonary disease. Available Partridge MR, Dockrell M, Smith NM. The use of complementary medicines by those with asthma. Respir Med 2003;97(4):436-8.

2. Jørgensen V, Launsø L. Patients' choice of asthma and allergy treatments. J Altern Com-plement Med 2005;11(3):529-34.

3. Schäfer T. Epidemiology of complementary alternative medicine for asthma and allergy in Europe and Germany. Ann Allergy Asthma Immunol 2004;93(21):S5-10.

4. Mokhtar N, Chan SC. Use of complementary medicine amongst asthmatic patients in pri-mary care. Med J Malaysia 2006;61(1):125-7.

5. Lewith GT, Watkins AD. Unconventional therapies in asthma: an overview. Allergy 1996;51(11):761-9.

6. Poitevin B. Review of experimental studies in allergy: clinical studies. Br Homeopath J 1998;87(02):89-99.

7. Linde K, Jobst KA. Homeopathy for chronic asthma. Cochrane Database Syst Rev 2000;(2):CD000353.

8. McCarney RW, Linde K, Lasserson TJ. Ho-meopathy for chronic asthma. Cochrane Da-tabase Syst Rev 2004;(1):CD000353.

9. Bellavite P, Ortolani R, Pontarollo F, Piasere V, Benato G, Conforti A. Immunology and homeopathy. 4. Clinical studies - Part 2. Evid Based Complement Alternat Med 2006;3(4):397-409.

10. Bellavite P, Chirumbolo S, Magnani P, Orto-lani R, Conforti A. Effectiveness of homeopa-thy in immunology and inflammation disor-ders. A literature overview of clinical studies. Homoeopathic Heritage International 2008;33(2)35-7.

11. McCarney RW, Lasserson TJ, Linde K, Brinkhaus B. An overview of two Cochrane systematic reviews of complementary treat-ments for chronic asthma: acupuncture and homeopathy. Respir Med 2004;98(8):687-96.

12. Ullman D, Frass M. A review of homeopathic research in the treatment of respiratory aller-gies. Altern Med Rev 2010;15(1):48-58.

13. Sharma B, Narula RH, Manchanda RK. Ho-moeopathy for the management of asthma: A review of Council's Clinical Research. In-dian J Res Homoeopathy 2015;9(2):69-78.14

14. Moher D, Liberati A, Tetzlaff J, Altman DG. PRISMA Group. Preferred reporting items for systematic reviews and meta-analyses: the PRISMA statement. BMJ. 2009;339:b2535. 
15. Liberati A, Altman DG, Tetzlaff J, Mulrow C, Gøtzsche PC, Ioannidis JP, et al. The PRISMA statement for reporting systematic reviews and meta-analyses of studies that evaluate health care interventions: explanation and elaboration. PLoS Me Chapman E. Homoeopathy. In: Jonas WB, Levin JS, editors. Essentials of Complementary Medicines: Lipincott Williams Wilkins [CD ROM] 1999.

16. Rossi E, Crudeli L, Garibaldi D. Cost-benefit evaluation of Hmoeopathy versus conventional therapy in respiratory diseases. Adi BS. Efficacy of homoeopathic medicines in chronic low back pain: a clinical study. International Journal of Alternative and Complementary Medicine. 2020, 17-20. Homoeopathy 2009;98:2-10.

17. Davidson S. Davidson's Principles and Practice of Medicine. Elsevier 2014.

18. Boericke W. Homoeopathic materia medica Dr R.G. Miasmatic table. $6^{\text {th }}$ edition of Organon of Medicine.

19. Subbarao P, Mandhane PJ, Sears MR. Asthma: epidemiology, etiology and risk factors. CMAJ 2009;181(9):E181-E190. Doi: 10.1503/cmaj.080612.

20. Sharma B, Narula RH, Manchanda RK. Homoeopathy for the management of asthma - A review of Council's Clinical Research. Indian $\mathbf{J}$ Res Homoeopathy 2015;9:69-78. 